\title{
Cycling and Disability: A call for further research
}

Dr William Clayton ${ }^{1}$ (Corresponding Author)

Research Fellow

University of the West of England, Bristol

William2.clayton@uwe.ac.uk

Professor John Parkin ${ }^{1}$

Professor of Transport Engineering

University of the West of England, Bristol

John.parkin@uwe.ac.uk

Chris Billington

Evaluation Officer

Sustrans

Chris.billington@sustrans.org.uk

${ }^{1}$ Centre for Transport and Society

University of the West of England, Bristol

Coldharbour Lane, Bristol, UK, BS16 1QY

2Sustrans

2 Cathedral Square

College Green, Bristol, UK, BS1 5DD 


\title{
Cycling and Disability: A call for further research
}

\begin{abstract}
Cycling can offer health benefits, and these benefits are relevant for disabled people. Few disabled people cycle, and disability is under-researched in cycling studies. This paper (i) reviews current research into disabled cycling, and provides a critique of inclusive cycle design guidance; and (ii) reports on a recent study which highlights some of the significant issues faced by disabled cyclists in accessing cycle infrastructure and using designated cycle networks. A semi-structured focus group was conducted with eight inclusive cycle scheme users, seven care providers supporting the majority of the cyclists, and the scheme organiser. We conclude that the needs of disabled cyclists are increasingly being taken into consideration in infrastructure design guidance, but there are many issues to be resolved before cycling is accessible to and usable by disabled people. There is little research on understanding the experiences of disabled cyclists, and hence there is a knowledge gap concerning the efficacy of current design guidance. The data presented in this paper provide a useful first insight into the experiences of a group of disabled cyclists, but these data are limited to the specific context of that group. Further research is needed.
\end{abstract}

\section{Keywords}

Cycling; disability; experience; design guidance; policy

\section{Introduction}

Cycling can offer significant health benefits to disabled people by improving fitness and mental wellbeing. It can also mitigate secondary conditions. These benefits mean that it is important that people with mobility impairments are not excluded from cycling. Disability remains an under-researched area within cycling studies, and in the UK there are low rates of cycling amongst disabled people. There is little funding for promotion in this area, and this is despite a good level of third-sector activity. This lack of focus may be a consequence of a perception that cycling is not an activity accessible to disabled people. However, this is not the case, particularly considering the availability of adapted cycles, which importantly are much cheaper than adapted cars.

The purpose of this paper is twofold:

(i) to review current research into disabled cycling, and provide a critique of inclusive cycle design guidance in relation to this; and

(ii) to report on a recent study which highlights some of the significant issues faced by disabled cyclists in accessing cycle infrastructure and using designated cycle networks.

In addressing these two aims, the paper serves as a call-to-action for the research community to put disabled cycling on the research agenda, fill the knowledge gaps that exist in this area, and assist in producing meaningful improvements to create inclusivity in cycle infrastructure.

Section one presents current statistics on disability, transport, active travel, and public health and wellbeing, to emphasise the importance of this area, and contextualise the subsequent discussion. Section two develops a review of existing types of adapted cycle, and a critique of current cycle design guidance in relation to its accessibility for disabled cyclists and adapted cycles. Section three outlines the methodology and provides the sample demographics. Section four presents the thematic analysis of the qualitative data, and section 5 expands on this, discussing it in relation to existing research. Section 6 draws together the conclusions, and suggests what the next stages should be in addressing the knowledge gap in this area.

\subsection{All ability and disability}

To consider cycling for those of all abilities, it is necessary to define the obverse - what a disability might comprise of - in order then to ensure that planning and design covers all needs. The United Kingdom Equality Act (2010) definition states that a person has a disability if they have a physical or mental impairment and the impairment has a substantial and long term adverse effect on their ability to perform normal day-to-day activities.

The Papworth Trust (2016) usefully summarises data on disability in the UK population. 
Approximately $19 \%$ of the UK population has a disability (DWP, 2014), with only $17 \%$ of those with disabilities having them from birth (Regan and Stanley, 2003). The prevalence of disability increases with age. Disability results in a person on average experiencing significantly different employment opportunities, lower income, and lower educational attainment. Mobility impairment is the most commonly-reported form of disability, with $57 \%$ of disabled people experiencing this (DWP, 2014). At the same time, most mobility impairment is relatively invisible, with only approximately $10 \%$ of disabled people using a wheelchair, for example (Papworth Trust, 2016). Consequently, it is likely that that mobility impairment, and the barriers people face in relation to this, are underappreciated in transport generally, and thus underrepresented in policy and design.

Transport is the largest concern for disabled people in their local area, with footway and road maintenance, access issues, and frequency of public transport being the biggest issues (ODI, 2011). Disabled people travel a third less often than the general public, and use buses, taxis and minicabs more often than the general population (TRIP, 2003). $75 \%$ of disabled adults experience barriers to using transport, compared with $60 \%$ of adults without a disability. These challenges posed by the existing transport network translate directly into issues of employment, with $29 \%$ of adults with impairments reporting difficulty with transport as a significant barrier to work (ODI, 2011).

Despite forming $19 \%$ of the population, disabled people make up approximately $33 \%$ of users of the NHS. Poor health is associated with low socio-economic status and those who have never worked or are long term unemployed have the highest rates of self-reported 'poor' health. Ells et al. (2006) found that disabling conditions have a significant positive statistical association with obesity. The relationship between obesity and disability is complex. Sometimes disability can be the cause of obesity - for example where a person with a mobility impairment is unable to engage in sufficient physical activity; in other cases, obesity can be the cause of disability - for example where excess weight can lead to conditions such as osteoarthritis. Often it is the case that both of these are true, and a disabled person can experience an accumulation of interrelated health issues over time.

\subsection{Physical activity, transport, and health}

Several studies in the wider cycling literature all identify a common element of the experience: quite simply, in the right conditions, cycling is immensely pleasurable (e.g. Clayton and Musselwhite, 2013; Horton et al., 2007; Spinney, 2006, 2009). This pleasure is related largely to the kinaesthetic and sensory experiences of cycling, the 'sense of exhilaration, or pure delight, in just experiencing motion without strain or struggle' (Taylor, 2003, p. 1617). Cycling creates a unique and intimate connection to the spaces through which people travel (Spinney, 2006, 2009), and can bring a sense of freedom and joy that other modes struggle to match (Clayton and Musselwhite, 2013). All of these enjoyable experiential attributes of cycling can have a positive impact on cyclists' wellbeing.

There is a well-established evidence base identifying the positive effects of physical activity on the health and wellbeing of disabled people (see: Durstine et al., 2000). Furthermore, physical activity can reduce the disease burden (WHO, 2000) and enhance wellbeing benefits partly linked with aspects such as the greater social connectivity that transport offers (Environment Canterbury, 2010; Betts Adams et al., 2011; Nordbakke and Schwanen, 2013).

Physical activity describes 'any force exerted by skeletal muscle that results in energy expenditure above resting level' (Casperson et al., 1985). Physical exertion is part of journey making. It may involve different proportions of walking, standing, or cycling as part of the journey. The intensity of physical activity may also vary, for example depending on the speed of cycling (Davis and Parkin, 2015). Some cycle users will exert to the level of vigorous activity for longer periods (Vuori et al., 1994).

Despite the benefits of physical activity, disabled people are less likely to engage in physically active lifestyles than are non-disabled people (Rimmer et al., 2004). This disparity can be attributed to the transport barriers faced by disabled people. Current data demonstrates a need for improvements to the transport network which can help address the accessibility gap observed between disabled people and their peers (Papworth Trust, 2014). Aldred and Woodcock (2008, p. 491) have explained that disabled people are 'disproportionately excluded from the streets', and experience lower rates of physical activity and higher rates of obesity as a result. The accessibility imperative is not just limited to the realm of active travel, but also 
public transport (Jones and Jain, 2006). The current car-centric design of the UK and many other developed world transport systems, means that people with a mobility impairment can only achieve a seamless journey (an essential factor in making a journey achievable) by relying on the private car (for example, either as a driver, a passenger or in a taxi).

However, the car is the mode least associated with beneficial physical activity and exertion (Maynard, 2009). Aldred and Woodcock (2008) have described the dominance of car travel as a disabling force at the societal level, raising barriers to access for populations larger than those conventionally identified as 'disabled', and creating a situation in which people are effectively disabled by their environment. Whilst all of those in the population who do not have access to a car must attempt to struggle over the barriers created by urban sprawl and carcentric development (e.g. infrequent or non-existent public transport, disjointed walking and cycling infrastructure, dangerous road crossings, and circuitous routes), for many disabled people these barriers are simply insurmountable; thus the current system effectively excludes disabled people to a greater or lesser degree from the broader personal travel domains beyond the car (Ibid; Maynard, 2009). If it were possible to provide greater transport opportunities for disabled people - particularly if the means involved physical activity - then significant elements of the socio-economic and health inequalities resulting from disability could be tackled simultaneously.

While some people may not be able to walk easily, they may, by contrast, be able easily to cycle. This may be because, for example, they have a hip problem which does not now allow comfortable perambulation, but, by contrast, does allow for the circular motion of pedalling. If someone is unable to use their legs to pedal, then they may be able to use their hands and arms and a hand-cranked bicycle may allow them greater locomotion than a foot pedalled cycle. While the ability to cycle with a disability may not be in question, there remain issues however about - for example - mounting and dismounting, walking alongside the cycle, balancing at very low speed or while static, and the ability to manoeuvre and successfully park the cycle. Cycle design that is inclusive needs to cater for those of all levels of experience and ability.

Training is also an issue, as many disabled people may not have cycled previously, and require practice to gain experience and remain safe - particularly if the intention is to use roads and paths shared with pedestrians. In respect of teaching disabled people to ride, Klein et al. (2005) report a methodology which includes innovative teaching techniques and specialised equipment. MacDonald et al. (2012) investigated the effect of a cycle training intervention for children with Down's Syndrome (DS) and autism spectrum disorders (ASD).

\subsection{Cross-benefits}

An important but often-overlooked aspect of inclusive infrastructure is the cross-benefit it brings, that is to say the benefit to non-disabled as well as disabled people. A truly inclusive network has a benefit for all cyclists, making the network more accessible and attractive to disabled and non-disabled cyclists alike. In debates about inclusive cycling in the UK, there is an implication that the inclusive elements of the cycle network are being instituted specifically for the benefit of those users with additional needs, for example disabled cyclists. An assumption persists that non-disabled 'bicyclists' are not a primary target of inclusive design features, and that this group might simply be expected to accept and navigate the various obstacles and hazards that typify much of the cyclists' experience of cycle infrastructure in the UK. The fact that cyclists without additional needs can traverse obstacles such as a poorly designed gates, steps and kerbs, broken paths, and narrow cycle lanes (albeit often with significant difficulty) is taken to mean that these obstacles are generally acceptable to many cyclists.

This implies that the general class of cycle user can live with the myriad infrastructural deficiencies, however as Hickman $(2015$, p. 7) notes, this is something of a fallacy when considering what all cyclists might expect from a truly acceptable and accessible cycle network: 'the requirement for a step-free network extends beyond the needs of disabled people'. A focus on inclusive infrastructure is therefore a 'win-win' scenario: the network becomes accessible to disabled cyclists, whilst simultaneously becoming more attractive to those that are already (or who are considering) using it. 
To highlight the barriers to cycling faced by many disabled people, it is necessary to understand the relationship between the design of adapted cycles and existing design guidance for cycle infrastructure. Adapted cycles have dimensions which are often larger than those of a typical bicycle design, and barriers can be created when the design guidance which is used by engineers in the construction of infrastructure does not sufficiently take these dimensions into account.

\subsection{Types of adapted cycle}

Cycles may often be used as what could be termed 'mobility aids' (Hickman, 2015), or cycles may be used as part of an overall journey with other mobility aids (TfL, 2014). Types of adapted cycle other than bicycles are illustrated in Figure 1. An electrically assisted cycle is not treated as a motor vehicle (Road Traffic Act 1988, Section 189).

Figure 1 - Types of adapted cycle

Tricycle
Handcycle
Recumbent
tricycle
Recumbent
Randcycle
quadricycles
Mixed
upright and
pedal / hand-
crank




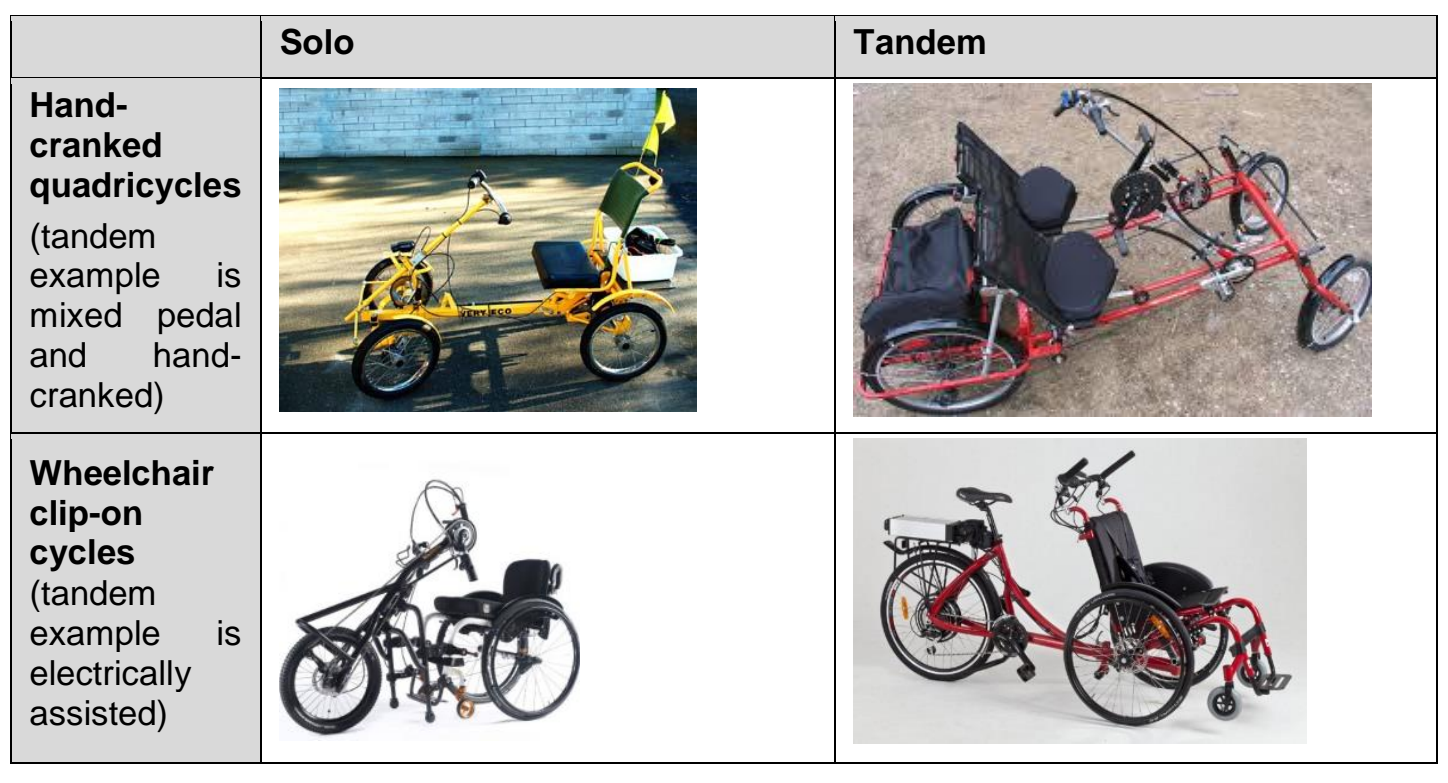

As well as what may be termed 'standard' adapted cycles as illustrated above, there may be other very specific adaptations made for the specific needs of certain types of users. Blumenstein et al. (2014), for example, report results of a trial of an electric bike adapted for use by youths with cerebral palsy. Conversely, it should be noted that some disabled people may cycle un-adapted bicycles. Hickman (2015) rides a Brompton folding bicycle with the aid of a leg prosthetic, and has described how the free mobility offered by the bicycle to some disabled people can often mask disability. This allows disabled people to 'fit into' the bicycling community, but contributes to their invisibility, helping reduce the apparent need for specific consideration of need.

\section{$2.2 \quad$ Current design guidance}

The consequences of not designing infrastructure appropriately are reported by Xiang et al. (2006) who found from United States data that disabled cycle users were five times more likely to have been hit by a motor vehicle than non-disabled cycle users. Public sector bodies are recognising their need to pursue inclusive street design (for example, TfL, 2014).

The genes of the Dutch cycle design guidance (CROW, 2006) can be traced forward into much other guidance that has been created in the UK and other countries. The central tenet of the guidance is that, in addition to the geometric engineering principles needed to develop any design for a vehicle capable of speed, the designer also needs to be aware of the special characteristics of the bicycle and rider. Rider characteristics influence design requirements which are defined as network coherence, directness, attractiveness, safety, and comfort. The Danes, despite very good general guidance on designing for cycles (Cycling Embassy for Denmark, 2012, and Celis Consult, 2014) make little specific reference to provision for cyclists of all abilities.

UK guidance in Local Transport Note (LTN) 02/08 (DfT, 2008) goes only so far as to say that users of 'specialised equipment' need adequate width and absence of pinch-points, 'sharp bends' and features that require a user to dismount. Commentators suggest (e.g. Parkin and Koorey, 2012) that this guidance for wider reasons needs to be revised and updated. LTN $1 / 12$ (DfT, 2012) was issued after the Equality Act (2010) and recognises that disabled people may be particularly 'affected' by shared use routes. As with LTN 02/08, however, consideration in respect of disability is principally towards those on foot.

The London Cycle Design Standards (TfL, 2014) suggest that infrastructure for cycle traffic should be designed in an inclusive way based on the concept of 'the inclusive cycle', and a point is made that a 'more forgiving environment' is required, although this is not well specified. Again, the emphasis is on avoiding narrow gaps, dealing with the turning circle, and the cycle's length.

Welsh Assembly Government (2014) guidance recognises that there is no homogeneity within disability and there is a range of design requirements. There is little specific guidance provided though, apart from the recognition that needs are quite different, but, on the contrary, the 
meeting of the needs of one group can benefit other groups.

The Design Manual for Roads and Bridges, written for strategic road network design but also widely used for local roads, has historically referenced cycle users inappropriately as 'nonmotorised users', with a presumption of similarity to pedestrians and equestrians. An updating Interim Advice Note (Highways England, 2016) addresses strategic road network design issues for cycle traffic specifically and caters for a 'cycle design vehicle'.

Separately from design guidance per se, Gray et al. (2012) review what they term 'universal design' instruments for the built environment in relation to disabled people. These instruments are questionnaires and audit tools rather than tools for assisting in the design development process. Forty-four of the ninety-five tools identified covered cycling either specifically or in part with approximately one-third of instruments including some disability-specific items.

In conclusion, it may be said that most guidance is sensitive to the issue of inclusive cycling. However, there is generally little specific detail addressing issues for users of inclusive cycles. This is not problematic if design requirements for the general class of cycle users adequately cater for disabled cyclists, and if such design guidance is adhered to. However, it is not clear that either of these conditions is ubiquitously met.

\section{$3 \quad$ Methodology}

\subsection{Context}

This section reports on a focus group and interview held with disabled cyclists, their attendant care providers, and the scheme organiser of a nascent inclusive cycling scheme in Bristol, UK. The data were collected for a project whose primary focus was broader than disabled cycling. As a part of the West of England Sustainable Travel (WEST) project, a number of community schemes in Priority Neighbourhoods have been allocated a grant through the UK government's Local Sustainable Transport Fund. The focus of this study is one of these community schemes: an inclusive cycling programme run by a cycling group set up to support cyclists with additional needs. The scheme places a particular focus on introducing people who might never have cycled before to the experience of using an adapted cycle. The scheme is managed by an employed scheme organiser, and run primarily by the scheme organiser with the help of volunteers (some of whom were also users of the scheme). The scheme is run as a service, and people pay a small sum for the hire/use of the adapted cycles.

The disabled cyclists who participated in the group had a range of cognitive and physical impairments. This range extended from people with a learning difficulty which made using a cycle and related infrastructure more challenging, and people with more profound combinations of cognitive and physical impairment which meant that they were unable to use a cycle without assistance. The majority of the participants utilised the support of a care worker or the scheme organiser when using the adapted cycles (most often a tandem).

\subsection{Procedure}

A semi-structured focus group was conducted with eight inclusive cycle scheme users, seven care providers supporting the majority of the cyclists, and the scheme organiser. Kroll et al. (2007) conducted a review of the use of focus groups in disability research, and concluded that they are a useful method, providing an inclusive forum and the opportunity for traditionally excluded people to give their views. At the same time, there are specific challenges presented, for example people using different means of communication, the use of proxy respondents (as with the care providers in this study), and the need to maintain balance inclusivity in the discussion within this context.

\section{Proxy respondents}

The use of proxy respondents is essential to assist people with limited communication skills (Bollard, 2003), however, they raise a number of important issues which must be managed. The value of qualitative research is in the richness of the data generated through people's recounting of personal experience (Barrett and Kirk, 2000); the use of proxy respondents means that there is an additional person added in between the researcher and participant, acting as a go-between or translator (Kroll et al., 2007). Primarily, this is a positive function, as it enables a researcher to communicate more fully with a participant that they otherwise might not be able to understand. At the same time, the proxy respondent might be adding their 
views and perspective in to the 'translations' of the participant's experiences.

The care providers were proxy respondents in our study, and their engagement was essential to assist the participants in explaining their experiences. To maintain as far as possible the integrity of the participants' responses, when a proxy respondent responded on behalf of a scheme user, the interviewers would confirm the contribution, asking, for example: "does that sound right to you?", "is that correct?", or "would you agree with that?". To which participants could indicate their confirmation or rejection of a statement. The interviewers would also double-check with care providers when they made a statement about their own experiences of providing assistance to the cycle scheme users of using the cycle scheme with them, and of the main issues and barriers as they saw them. The care providers in these instances would be asked them to confirm that this was their own view.

Whilst the use of proxy respondents is something which requires careful management, it should be noted that these are respondents often know the participants very well, and who can both be very helpful in facilitating the participants' inclusion, and also in providing their own perspective on their experiences of assisting the participant.

\section{Recruitment}

Participants were recruited through the inclusive cycle scheme organiser. Details of the study were sent to the scheme organiser, who discussed it with potential participants and recruited those who were interested in joining the discussion. Recruitment of the care providers who participated was achieved by virtue of their supporting the scheme users. The purpose of the focus group was explained in detail to all participants before the discussion started, and it was made clear that people did not have to take part if they did not wish to do so. Participants signed a consent form for their taking part, and were told that if they subsequently decided they were no longer happy to be involved, to inform the scheme organiser who would contact the research team and request the withdrawal of their data. In practice, the discussion was a very positive and productive one; participants engaged enthusiastically and appeared eager to give their views on their experiences of using the inclusive cycling scheme.

\section{Group size and composition}

The sample composition is presented in Table 1.

Table 1 - Sample characteristics

\begin{tabular}{|l|l|l|l|l|}
\hline & $\begin{array}{l}\text { Disabled } \\
\text { cyclists (DC) }\end{array}$ & $\begin{array}{l}\text { Care } \\
\text { providers (CP) }\end{array}$ & $\begin{array}{l}\text { Scheme } \\
\text { organiser (So) }\end{array}$ & Total \\
\hline $\begin{array}{l}\text { Total } \\
\text { number }\end{array}$ & 8 & 7 & 1 & 16 \\
\hline Gender & $\begin{array}{l}\text { Male: } 5 \\
\text { Female: } 3\end{array}$ & $\begin{array}{l}\text { Male: } 3 \\
\text { Female: } 4\end{array}$ & $\begin{array}{l}\text { Male: } 1 \\
\text { Female: 0 }\end{array}$ & $\begin{array}{l}\text { Male: } 9 \\
\text { Female: } 7\end{array}$ \\
\hline
\end{tabular}

\section{Setting characteristics}

To accommodate disabled participants' needs, the focus group was held in a familiar, accessible location. The location used had accessible parking, entranceways, and bathrooms, and was a place that all of the participants had visited relatively frequently before.

\section{Focus group conduct}

Discussion in the group focussed on the experience of cycling and the benefits and challenges of using adaptive technology both on and off the designated cycle network. For most questions, participants were given the opportunity to respond individually to give everyone a chance to contribute, before the discussion was opened up for people to add other experiences and perspectives.

Participants were asked questions on their use of the scheme, their experiences of cycling 
both in the more general sense and in specific relation to the provisions of the scheme, whether they had encountered any barriers to cycling, and what they thought the impacts of the scheme were. The scheme organiser was asked additional questions in the follow up interview, concerning the origins of the scheme, its broader impacts, and any challenges to its operation.

A follow-up interview was held with the scheme organiser to explore the benefits and challenges to the operation of the scheme. Both the focus group and the interview lasted for approximately 90 minutes each.

The data were transcribed subjected to thematic analysis using NVivo software. Participants' data has been anonymised through the use of pseudonyms.

\section{$4 \quad$ Results}

The results from the study are presented under the themes identified by the analysis: 'Experiences of cycling'; 'Health and wellbeing impacts'; and 'Barriers to disabled cycling'. These represent the topics that participants discussed most frequently, and also which they described as being the most important and relevant. Within each of these overarching themes, there were a number of more specific and distinct sub-themes discussed by participants, and these are identified in each section.

\subsection{Experiences of cycling}

This section covers three main sub-themes related to the experience of cycling: first experiences of cycling, confidence on cycles, and kinaesthetic pleasure.

The scheme has eleven adapted cycles in a variety of different configurations to suit users' varying needs. The inclusive cycling scheme focusses predominantly on leisure cycling with the aim of increasing the health and wellbeing of the users:

For many of the people in the group, the adapted cycle was their first experience of being on a cycle, and this was generally agreed to be having a positive benefit for the users:



The inclusive cycling centre provides an off-road space for people who had not experienced cycling before to practise before journeys in and around Bristol were made.

There were a range of different benefits associated with cycling using the adapted cycles. The most commonly discussed was simply the increase in confidence that riding the adapted cycles could engender in the users:

"What I have found great is just the progression of people's confidence on the bikes. I have a lady that comes along every Thursday and uses the tag along with me, and I go out with her and she doesn't pedal at all and I'm like, "come on [Debbie] pedal!" And she is like "I am!" and I get to the top and I'm about to die, and then I go back down the hill. Then yesterday I was like "shall we try and use your legs today?" - and this is probably the third month she has been using the service and we were doing up the hill - and I was thinking "this is much easier than normal", and she finally figured out how to do her legs and she just loved it and was over the moon. So there are the moments you go "yes, I'm glad we're doing this". She got a lot from that." (SO - Interview)

For the disabled cyclists, one of the main positive aspects of the experience was simply the same pleasurable kinaesthetic sensations so often associated with cycling. Cycling was described as fun and exhilarating by the cyclists and care providers, and there was discussion of experiences of speed and flow, which for most of the scheme's users were completely novel:

"I like going really, really fast!" (DC-2)

"We are using it [...] purely for the pleasure of cycling in that area at the time that we go there. We have never really had access to these kinds of facilities." (CP-3)

\subsection{Health and wellbeing impacts}


This section discusses four sub-themes related to the reported health and wellbeing impacts of disabled cycling: health improvements, confidence in other cycling contexts, involvement in the running of the scheme, and community/social inclusion.

Several people discussed the perceived health benefits of cycling for disabled people. Whilst the participants in the group most often went on supported rides, nonetheless this was seen to improve people's health as well as increasing their wellbeing and confidence:

"Yes [Gerry] gets on the side of it with [SO] and he loves it. Where before he wouldn't go on a bike he wouldn't even attempt to get on the bike he wouldn't even attempt to go on a bike but now he looks so much healthier [...]. But it is [Gerry]'s highlight of the week he loves it." (CP-6)

One disabled cyclist explained in clear terms the positive effect that cycling was having on his health:

"I went for a check-up and they said my blood pressure has really dropped." (DC-5)

For some, the experience of cycling in the group had given them the confidence to cycle elsewhere:

"[Poppy] recently went on holiday to one of the big Butlin's camps and they had fourwheel bikes there for two people to sit on but they actually ended up giving her one for the whole week because she wouldn't get off it! I think I lost about 12 pounds on that weekend." (CP-3)

Improvements to health can be attributed to the act of cycling itself, however there were wider wellbeing benefits of the inclusive cycling scheme which went beyond just the physical exercise. Foremost of these was the opportunity the scheme provided for people whose disability made regular employment impossible to help with the running of the scheme and the maintenance of the fleet - activities in which people placed great value:

"[Gordon] comes down and helps out. He does some oiling for me and stuff, and he meets and greets and helps with that." (SO)

"It gives the service users a chance to come down and do a voluntary job where they are supported and they are outdoors and there is a café there. [Annie] really enjoys it [...] and she had never cycled before but I think it gives my service users a chance to feel like they are doing a job. [Annie] has put oil on the chains and handed out helmets and got the bikes out [...] so from that aspect it has been very beneficial." (CP-7)

This aspect of the data is evidently only relevant to people whose disability precludes them from the experience of working. As discussed earlier, a large proportion of disabled people are able to work and would be using adapted cycles for different purposes (e.g. commuting). In the context of this group of disabled cyclists however, the broader benefits of involvement in an inclusive cycling scheme are very evident and relevant.

The physical setting of the scheme was also important in creating additional wellbeing benefits in the form of community engagement and social inclusion. The scheme's headquarters are situated alongside one of the main National Cycle Network routes, adjacent to a local café which is a popular stopping place for other route users. This means that the people using the adapted cycle can go out onto the cycle network and experience the surrounding area in a new way.

The benefits here were seen to be both physical and social. From a physical perspective, some scheme users were able to use the designated space of the cycle network to venture further than they would have done on the road, and it was evident that the infrastructure played a key role in enabling greater levels of cycling for people:

"But it is lovely [on the cycle path] because you can... [Gerry] can be pushed to go further, but now it goes further and further." (CP-6)

From a social perspective, the proximity to the cycle path provided an opportunity for the disabled cyclists to experience being a part of the general cycling crowd, and respondents suggested there was a welcoming atmosphere for those using adapted cycles:

"They are so lovely there and you do get all the regulars that come along every day 
as well and they are really supportive as well. It does feel like a nice little community hub. They are all such a nice bunch. People on the cycle path are also very receptive and we see them honking their horns, and so yeah respectful and enthusiastic about it." (SO - Interview)

\subsection{Barriers to disabled cycling}

This section discusses four sub-themes related to the reported barriers to disabled cycling: infrastructure, social conflict, costs of adapted cycles, risk of loss, and risk of breakdown.

With relevance to earlier discussion of cycle design guidance, one participant noted that the design of the path could create a barrier for those using an adapted cycle

"In terms of access, they were cycling to [village] on the side by side bike and they were manoeuvring through all the little bollards there and the only problem there is when you get to the cycle path you get to the [village] side you can't get the bike through at all so if they could just widen it slightly... Because [...] if you just widen it a little bit it makes it more accessible for people on these kind of bikes." (SO)

The scheme organiser described the importance of considering the social context of the cycle path in relation to people's experiences of using a public path and interacting with strangers. Whilst in general, being a part of the cycling community and interacting with others on the path was a positive thing for participants, it also was one of the things which could create a negative experience for people with a social impairment who might find social interactions more challenging:

"So I had said to the support worker that was supporting this guy, "do you feel confident enough that he is going to be okay on the cycle path? He must keep left." And she said "ah yeah, he will be fine". So she took him out and came back about 30 mins later crying his eyes out. So I was like, "what happened?", and he was on the wrong side of the road and [...] there was a guy speeding down and he just got a telling off. Unfortunately, the service user has never been back. He was really enjoying it but just something like that can really put you off." (SO - Interview)

"So for some people the cycle track is too fast you know you have some people bombing down on the racing bikes and everything else and it is just too fast." (CP-3)

"I do find some cyclists are a little bit annoying. Like you will be going along and there will be someone bombing it and it's like, hold on... It is everyone's path not just yours." (SO - Interview)

During the discussion, a number of further barriers were identified which made cycling more challenging for the participants. A barrier mentioned regularly was cost. Adapted cycles are often significantly more expensive than the average bicycle, and because of this disabled people may not be able to access one:

"As individuals [service users] couldn't afford to buy them [adapted cycles]. [...] These bikes are expensive, you know and as soon as you specialise them the pound signs [E] keep ticking away... By bringing the bikes together we are actually able to use them together." (CP-3)

In this respect the inclusive cycling group was seen to remove the price barrier for people by providing access to the cycles for a small fee, as opposed to people having to buy one for themselves:

"This kind of equipment has always been too expensive for individuals to have within the home and stuff like that. So to have it in one place where we can go along and have it at various different times and use it in a safe environment is kind of what we are doing and we are using it like that. It is actually opening up the whole cycling thing in a more user friendly kind of way." (CP-3)

Evidently it is not the case that for all (or even most) people experiencing a disability the price of an adapted cycle will be too high (and indeed as Aldred and Woodcock (2008) explain, an adapted cycle is often considerably cheaper than a car), however, when combined with the earlier statistics relating to the relatively reduced rates of employment amongst those with a 
disability compared to those without, it is clear that price remains a crucial factor in the accessibility of cycling for a large number of people who require an adapted cycle.

Attached to the barrier created by high cost, is the issue of high value and the subsequent risk of theft.

"Leaving it there and locking it would just be dangerous because the bike is worth six thousand pounds [£]." (SO)

Fears about the safety of the high-value adapted cycles means that people may be unwilling to leave them locked up in a location that is perceived as being insecure, and this will limit the accessibility of certain areas or parts of the cycle network. Potentially the requirement for the provision of more secure cycle parking facilities at key points along cycle paths could help alleviate this.

Another participant spoke about the difficulty she encountered when one of the adapted cycles broke down during a ride, and some distance from the headquarters. For a person with mobility issues, an adapted cycle can be a freeing vehicle which allows them to overcome some of the mobility restrictions they face. However, if that vehicle does break down, then a person with restricted mobility might find themselves in a difficult situation if they were unable to continue (or backtrack) without the use of the cycle as their mobility aid:

"Me and [scheme provider] go out on the bikes together, but then the bike broke down. The pedal came off. We were so far aware form where [scheme provider]'s office is we had to carry it back. So I said to [scheme provider] the top question of the day is, "what happens if we break down?" (DC-5)

Other barriers described by the group mainly centred around specifics of the scheme itself, including funding and staffing - particularly in the context of disabled cyclists who require someone to support them during a ride:

"We aren't open as much as we would like to be. That is limiting as well for people particularly for families that want their kids to come down after school and we can't offer that quite yet because they would have to pay me to do that and that would cost them a lot of money." (SO - Interview)

Despite the range of barriers discussed in the group, by far the dominant narrative was of the value of cycling to disabled people and the need for improved support in this area to broaden the reach of inclusive cycling and get more people out and about:

"I'm sure some people would be there every minute of the day if they could. We would use it a lot more than we do now if we had the funding to be able to provide staff support and all that kind of stuff." (CP-3)

"[The project's biggest achievement is] the increased interest and seeing the progress of people as they are getting better and better at their cycling and their level of fitness improving, and that is really nice especially if they are enjoying it. [...] Just seeing that it is making an improvement in people's lives. Is that a bit cliché?" (SO Interview)

\section{$5 \quad$ Discussion}

This study has generated a set of findings which are relevant to the disabled cycling, and the threads revealed could form the foundations for a coordinated programme of research activity in this under-researched area in due course.

Cycle design guidance has been developing, and recognition of disabled cyclists' needs is frequently noted usually in relation to cycle dimensions (e.g. DfT, 2008; TfL, 2014). However, there remains little detailed and specific guidance (Parkin and Koorey, 2013). The data presented in this paper detailing disabled cyclists' experiences show the issue of cycle dimensions remains an issue, and will require remedial action to overcome deficiencies in practice. The discussion with participants has served to further highlight the critical nature of the accessibility issue for disabled cyclists. Whilst poor and inadequate infrastructure is a frustration to cycling for all cyclists, for disabled cyclists often this makes infrastructure wholly inaccessible, and thus is a directly limiting factor in disabled people's ability to maintain an active lifestyle, and to receive the health and wellbeing benefits of doing so. 
A number of significant issues have been identified in the focus groups. Disabled cyclists experience the same pleasures and frustrations of cycling as non-disabled cyclists, such as the enjoyment of the sensory experience and the feelings of freedom on the one hand, and on the other hand the occasional difficult interaction with other users (including cyclists) and the barriers created by poor infrastructure. This supports earlier discussion of the wider cycling literature, and the experiences of joy and exhilaration that cycling is reported to bring to all cyclists (Clayton and Musselwhite, 2013; Horton et al., 2007; Spinney, 2006, 2009; Taylor, 2003). Cycling was providing a clear health benefit for a number of the participants, improving mobility and fitness. Cycling was also providing a number of wellbeing benefits related to confidence on cycles and in different cycling environment, and in community engagement and social inclusion - this latter point combating to a degree the 'exclusion from the streets' often experienced by disabled people (Aldred and Woodcock, 2008). The findings confirm the wellestablished links between an active lifestyle and positive health and wellbeing outcomes for disabled people. Our findings emphasise the critical importance of a focus on disabled cycling as a straightforward and achievable method of addressing the current disparity in levels of physical activity between disabled and non-disabled people (Rimmer et al., 2004). Cycling is a form of physical activity which is often very possible for disabled people, more-so than walking, and this makes it an opportune route by which to assist people in improving their health and wellbeing.

At the same time however, there are a number of specific infrastructure and support needs which relate either solely or principally to disabled users. The requirements for support vary depending on the type of impairment a person experiences.

Adapted cycles are often relatively expensive. Aldred and Woodcock (2008) have suggested that adapted cycles are most often cheaper than cars, and whilst this may be the case, they are not much cheaper, with the price discussed by participants as around $£ 6,000$. This is significantly more expensive than a traditional bicycle, by approximately 10 times. This means that adapted cycles currently are not that accessible for a majority of people, particularly when considering the earlier evidence that disability results in a person on average experiencing significantly different employment opportunities and a lower income (DWP, 2014). One potential solution to this might be in the form of government support with the costs of an adapted cycle, which would make these more accessible to a greater number of people, and potentially create very large health and wellbeing benefits. This could be seen as a health intervention. Related to the high cost, adapted cycles were seen as being particularly at risk of theft. In the case reported in the data, this is a limiting factor because the worry of locking up the bike in an insecure location meant people simply would not go further and park at a destination. This limits the value of cycling for transport purposes. Infrastructural improvements including enhanced security (e.g. lockable shelters) at key locations along routes might help address this barrier.

Participants also discussed the experience of breaking down on a cycle, and this was described as a particularly significant event for a person with a mobility impairment. When considered in the context of a disabled cyclist riding alone, the situation could be more serious due to the fact that the cycle is often acting as a mobility aid (Hickman, 2015), and the user could find themselves stranded. Consideration could again be given here to the mitigation of such a crisis through infrastructure design - for example through the provision of simple public repair stations along key routes, regular seating/recovery areas. And of course, these would be valuable to all riders.

These findings suggest that there are significant benefits to increasing participation in disabled cycling, but that there is a pressing need for improvements in a number of areas to make this feasible, mainly, infrastructure design and delivering cycling as a comprehensive service including both the instrumental and non-instrumental elements of the experience. There is a need to undertake further research in order to better inform in greater detail how this can happen.

\section{Conclusions}

The health and wellbeing benefits of cycling for disabled people are evident - encouraging fitness, enjoyment, and freedom. This review has highlighted that the needs of disabled cyclists are increasingly being taken into consideration in infrastructure design guidance, but that there are many issues to be resolved before cycling is accessible to and usable by disabled people. The review has highlighted a significant gap in the literature in terms of 
understanding the experiences of disabled cyclists, and what this can tell us about the ways in which current design guidance is either meeting or neglecting peoples' needs.

The data presented in this paper provide a valuable first insight into the experiences of a group of disabled cyclists, but these data are limited to the specific context of that group. The nature of the participants' disabilities will shape to a degree the experience of cycling and also the perceived benefits and barriers. Further research is needed to understand the range of different contexts in which disabled people are cycling, particularly for transport purposes, and what the specific requirements might be. This study is a call-to-action for the cycling research community to investigate further this important area, to fill knowledge gaps, and to contribute to the development of specific and helpful guidance for designers and promoters of cycling.

\section{References}

Aldred, R., Woodcock, J. (2008) Transport: Challenging disabling environments. Local Environment, 13 (6), pp485-496.

Barrett, J., \& Kirk, S. (2000). Running focus groups with elderly and disabled elderly participants. Applied Ergonomics, 31, 621-629.

Betts Adams., K., Leibrandt, S., Moon,H. (2011) A critical review of the literature on social and leisure activity and well-being in later life. Ageing and Society: 683-712. doi:10.1017\S0144686X10001091

Blumenstein, T., Zeitlmann, H., Alves-Pinto, A., Turova, V., Lampe, R. (2014) Optimization of electric bicycle for youths with disabilities. SpringerPlus 3:646 Springer Open Journal http://www.springerplus.com/content/3/1/646

Bollard, M. (2003). Going to the doctor's: The findings from a focus group with people with learning disabilities. Journal of Learning Disabilities, 7, 156-164.

Casperson, C., Powell, K., Christrensen, G. (1985) Physical activity, exercise and physical fitness: definitions and distinctions of health-related research, Public Health Reports, 100: 126-131.

Celis Consult (2014) Handbook for cycle traffic. Celis Consult, for Danish Government.

Clayton, W., Musselwhite, C. (2013) Exploring changes to cycle infrastructure to improve the experience of cycling for families. Journal of Transport Geography, 33 (2013), pp. 54-61

CROW, (2006) Design manual for bicycle traffic. (Dutch version April 2006, English version June 2007). Ede, The Netherlands: Centre for research and contract standardisation in Civil Engineering.

Cycling Embassy for Denmark (2012) Collection of cycling concepts. Cycling Embassy for Denmark.

Davis, A. and Parkin, J. (2015) Active travel: its fall and rise. In: Barton, H., Thompson, S., Burgess, S. and Grant, M. (Eds.) The Routledge Handbook of Planning for Health and Well-Being: shaping a sustainable and healthy future. Abingdon: Taylor and Francis/Routledge. Chapter 8

DfT (2008) Local Transport Note 02/08 Cycle Infrastructure Design. Department for Transport, London, UK.

DfT (2012) Local Transport Note 1/12 Shared use routes for pedestrians and cyclists. Department for Transport, London, UK.

Durstine, J.L., Painter, P., Franklin, B.A., Morgan, D., Pitetti, K.H., and Roberts, S.O. (2000) Physical Activity for the Chronically III and Disabled - Review article. Sports Medicine, 3, pp207-219.

DWP (2014) Family Resources Survey 2012/13, (online). Department for Work and Pensions, London, UK. Available from: https://www.gov.uk/government/statistics/family-resources-survey-2012-to-2013

Ells, L.J., Lang, R., Shield, J.P.H., Wilkinson, J.R., Lidstone, J.S.M., Coulton, S., Summerbell, C.D. (2006) Obesity and disability - a short review. Obesity Reviews, 7 (4), pp341-345.

Environment Canterbury Regional Council (2010) Wider health and well-being impacts of transport planning: Literature Review. Canterbury: Environment Canterbury Regional Council/Canterbury District Council/Christchurch City Council.

Gray, J.A., Zimmerman, J.L., Rimmer, J.H. (2012) Built environment instruments for walkability, bikeability, and recreation: Disability and universal design relevant? Disability and Health Journal 5, pp87-101

Hickman, K. (2015) Disabled cyclists in England: imagery in policy and design. Proceedings of the Institution of Civil Engineers: Urban design and planning.

Highways England (2016) Interim Advice Note 195/16 Cycle Traffic and the Strategic Road Network. Design Manual for Roads and Bridges. Available at http://www.standardsforhighways.co.uk/ha/standards/ians/pdfs/ian195.pdf (accessed 16th November 2016)

Horton, D., Rosen, P., Cox, P., 2007. Cycling and Society. Ashgate, Aldershot, UK.

Jones, T., Jain, J. (2006) Examining the experiences of sight-impaired travellers: The next station stop? The British Journal of Visual Impairment, 24 (3), pp141-144.

Klein, R., McHugh, E., Harrington, S. L., Davis, T., Lieberman, L., (2005) Adapted Bicycles for Teaching Riding Skills. Teaching Exceptional Children 37 (6), pp50-56.

Kroll, T., Barbour, R., Harris, J. (2007) Using Focus Groups in Disability Research. Qualitative Health Research, 17, 5, pp.690-698.

MacDonald, M., Esposito, P., Hauck, J., Jeong, I., Hornyak, J., Argento, A., Ulrich, D.A. (2012) Bicycle Training for Youth With Down Syndrome and Autism Spectrum Disorders. Focus on Autism and Other Developmental Disabilities 27(1) pp12-21

Maynard, A. (2009) Can measuring the benefits of an accessible transport enable a seamless journey? 
Journal of Transport and Land Use, 2 (2), pp21-30.

Nordbakke, S., Schwanen, T. (2013) Wellbeing and mobility: a theoretical framework and literature review focusing on older people. Mobilities.

ODI (2011) ODI Life Opportunities Survey Wave One results, (online). Office for Disability Issues. Available from: https://www.gov.uk/government/statistics/life-opportunities-survey-wave-one-results-2009-to-2011

Papworth Trust (2016) Disability in the United Kingdom 2016. Facts and Figures. Papworth Trust. Available from: http://www.papworthtrust.org.uk/

Parkin, J. and Koorey, G. (2012) Network planning and infrastructure design. In: Parkin, J. Cycling and Sustainability. Bingley: Emerald. Chapter 6.

Regan, S., Stanley K. (2003) Work for Disabled People - The Achilles heel of Labour's welfare-to-work agenda? Institute for Public Policy Research (online). Available from: http://www.ippr.org/uploadedFiles/research/projects/Social Policy/Work\%20for\%20disabled\%20-\%20Archi lles(1).pdf

Rimmer, J.H., Riley, B., Wang, E., Rauworth, A., Jurkowski, J. (2004) Physical Activity Participation Among Persons with Disabilities: Barriers and Facilitators. American Journal of Preventive Medicine, 26 (5), pp419-425.

Road Traffic Act (1988) HMSO. London. 1988.

Spinney, J., 2006. A place of sense: a kinaesthetic ethnography of cyclists on Mont Ventoux. Environment and Planning D 24 (5), 709.

Spinney, J., 2009. Cycling the city: movement, meaning and method. Geography Compass 3 (2), 817-835.

Taylor, N., 2003. The aesthetic experience of traffic in the modern city. Urban Studies 40 (8), 1609.

TfL (2014) London Cycle Design Standards. Transport for London: London.

TRIP (2003) Attitudes of Disabled People to Public Transport, (online). Transport Research and Innovation Portal. Available from: http://www.transportresearch.info/web/projects/project details.cfm?id=7441 andpage $=$ contact

Vuori, I., Oja, P., Paronen, O. (1994) Physically active commuting to work - testing its potential for exercise promotion, Medicine and Science in Sports and Exercise, 26(7): 844-850.

Welsh Assembly Government (2014) Design Guidance Active Travel (Wales) Act 2013. Welsh Assembly Government.

WHO, 2007 Economic assessment of transport infrastructure and policies: Methodological guidance on the economic appraisal of health effects related to walking and cycling, Copenhagen: Denmark.

Xiang, H., Zhub, M., Sinclair, S.A., Stallones, L., Wilkins, J.R., Smith, G.A. (2006) Risk of vehicle-pedestrian and vehicle-bicyclist collisions among children with disabilities. Accident Analysis and Prevention 38 (2006) 1064-1070 